\title{
Reforms of Biotechnology Experiment Teaching System in Local Universities: An Example from Hunan University of Humanities, Science and Technology
}

\author{
Yihong $\mathrm{Hu}^{1,2, \mathrm{a}^{*}}$, Zihan Mei ${ }^{1,2, \mathrm{~b}}$, Chenzhong Jin ${ }^{1,2, \mathrm{c}}$, Xujiao Zhang ${ }^{1,2, \mathrm{~d}}$ \\ ${ }^{1}$ Hunan Provincial Collaborative Innovation Center for Field Weeds Control, Loudi 417000, Hunan, China \\ ${ }^{2}$ Key Laboratory of Harmless Application of Pesticide in Hunan Higher Education, Hunan University of Humanities, Science and \\ Technology, Loudi 417000, Hunan, China \\ a*Email: huyhongwangyi@163.com, ${ }^{\mathrm{b} E m a i l:} 296010474 @ q q . c o m,{ }^{\mathrm{c} E m a i l: ~ 532479626 @ q q . c o m, ~}{ }^{\mathrm{d} E m a i l: ~ 380711974 @ q q . c o m, ~}$ \\ *Corresponding author
}

\begin{abstract}
The biotechnology specialty has been founded in many local universities over the last decade, therefore, how to build up a suitable experiment teaching system to cultivate specialized talents in biotechnology specialty for the local economic construction becomes an urgent task facing these universities. In this paper, the reforms of biotechnology experiment teaching system in Hunan University of Humanities, Science and Technology were taken as an example, and the problems existed in the biotechnology experiment teaching were analyzed. Moreover, the solutions to these problems were put forward such as the improvement of instruments, the enhancement of the construction of experimental teaching staffs, and the changes on experimental curriculum system, which will provide valuable references for the construction of local universities of the same kind.
\end{abstract}

Keywords-Biotechnology specialty; Local universities; Experiment teaching system; Reform

\section{INTRODUCTION}

Biotechnology is a kind of practical subject emphasizing on culturing the manipulative ability of undergraduate students especially in the local universities. The biotechnology experiment system should be based on promoting the manipulative ability, the comprehensive experiment ability, and the innovative experiment ability of students accordingly [1-3]. In the past ten years, a large number of technical colleges and teachers' colleges were upgraded to undergraduate universities in China, and the biotechnology specialty has been set up among some of these local universities these years. In most cases, the biotechnology experiment teaching system in these universities was simply according to the comprehensive universities, or was just made a limited modification, causing that the plan of experiment teaching was out of line with the personnel training goal of the specialty in the local universities, to result in a poor training result in reality. In this study, the main problems in biotechnology experiment teaching system in the local university were investigated and analyzed. The objective of this study is to explore a suitable biotechnology experiment teaching system so that the personnel training goal of the specialty in the local universities can adapt the local demand for biotechnology talents.

\section{PROBLEMS ENCOUNTERED IN BIOTECHNOLOGY EXPERIMENT TEACHING}

\section{A. Equipments were not applied with teaching demand}

In the recent years, biotechnology has been developing rapidly, and more and more new sophisticated equipments have appeared and put into use in this area worldwide. Since the local universities are supported by the local governments, the local governments are mainly responsible for the construction of biotechnology laboratory. Although these universities have been supported by some of the projects of central government to promote the conditions of laboratory during the past years, most of them are still plagued by a shortage of enough funds to improve the experimental teaching conditions. Meantime, owing to the fact that the researching abilities of teachers in these universities are in a relative weaker level compared with those in the comprehensive universities, the teachers themselves in the local universities are not able to purchase equipments to use for teaching through the expenses of their scientific projects.

\section{B. Construction of team of experimental teachers was restricted}

Stimulated by the policies of the undergraduate teaching evaluation and authorized degree evaluation by the Ministry of Education and the national "Double First-rate" strategic plan, the local universities have now paid more attention to introducing talent persons to meet with the assessment demands. Since the location of local universities belongs to the teaching type, aiming mainly at the culturing of undergraduate students, the staffing size is limited. Consequently, these universities trend to introduce high-level talents instead of experimental teachers. Furthermore, the experiment teaching in 
these universities has not been independent and is still an accessory of the theory teaching. Generally, the experiment lessons are still hold by the leading teachers, and then the laboratory staffs are only in charge of the experiment preparation and daily laboratory management. Thus, the laboratory staffs are just on the teaching assistance posts and their treatments are much lower compared with the leading teachers. For these reasons, they will not be working comfortably under these circumstances and it is difficult for the universities to enroll higher level laboratory staffs. On one hand, most local universities are suffering from a staffing shortage; on the other hand, few people are willing to work in laboratory, and the experiment teaching and laboratory management become the part-time job of the leading teachers and professional teachers. Thus the effectiveness of experiment teaching is seriously influenced.

\section{Experiment lessons were not settled reasonably}

In the local universities, the performance assessments of the teachers are mainly according to their teaching workloads because teaching is their most important responsibility. On this occasion, class hours sometimes are equally distributed among courses, causing that the experimental class hours of elementary courses are redundant, and those of professional basic courses and professional courses are far from enough. For example, when the basic course plant biology and the professional course genetic engineering are both arranged for eight experiments, the problem arises. As for plant biology, only microscope is often used, and most of the experiments are observing and verifying experiments. Students are not interested in numerous observing and verifying experiments. As for genetic engineering, it includes a serial of successive experiments and should be done continuously, and the same class hours are obviously inadequate. The students cannot fulfill the procedure well in due time to master the experimental skill only through eight experiments. In addition, the budgets for experiments are often accounted by experimental hours, resulting that the biotechnology experiments are always in short of experimental expenses, and some comprehensive experiments and designing experiments cannot be finished well. It should be mentioned that in some local universities, the demonstrative experiments are often adopted instead of the comprehensive experiments, leading to a poor teaching result.

\section{MEASUREMENTS TO IMPROVE BIOTECHNOLOGY EXPERIMENT TEACHING SYSTEM}

\section{A. Increase investment of biotechnology equipment}

Biotechnology is a fast changing and developing specialty, it faces directly to the scale productive practice in industry, and the applicability and generality of these equipments are generally weak. The equipment renewal rate of this specialty should be apparently higher than other science and engineering specialties. Hunan University of Humanities, Science and Technology has enhanced the construction of biotechnology specialty according to the talents need of the local region in recent years. Since 2012, our university has spent RMB 5.2 million to build experimental compartments for biotechnology specialty, the undergraduates can fulfill the basic experiments with one set of equipment per person, and fulfill the comprehensive experiments with one set of equipment every two persons. Based on this foundation, our university successfully applied the financing support RMB 6.3 million from the central government and the provincial government to purchase sophisticated equipments including high performance liquid chromatography (HPLC), high performance gas chromatography (HPGC), HPLC-mass spectra, GC-mass spectra, capillary electrophoresis, etc., to enforce the biotechnology teaching platform. Moreover, more than seven of the cooperative platforms between our university and the local scale enterprises have been founded to provide a better practice environment for training undergraduate students in the biotechnology specialty.

\section{B. Enhance biotechnology experimental staffing}

There were only two laboratory technicians in the biotechnology specialty in 2007 in our university when the specialty was founded first. At that time, the laboratory staffs were only in charge of equipments management, and the teachers in this specialty taught biotechnology experiments during the whole course. Up to now, there are four laboratory staffs in charge of biotechnology experiments teaching, and over $70 \%$ of the experiments were established independently from the theory lessons. At the same time, the university promoted the treatment and income of the laboratory staffs according to the standard of ordinary teachers, obviously improving the motivation of the laboratory staffs.

\section{Reasonably set class hours for biotechnology experiments}

During the preliminary stage when the specialty was founded, almost most of the class hours were equally distributed among basic courses, professional basic courses, and professional courses in our university. In light of this situation, discussions and meetings were hold among the teachers in the teaching and research section, and the teaching plan and personnel cultivating mode were revised accordingly. The experiment class hours of basic courses such as plant biology and zoo biology were condensed from 24 class hours to 18 class hours, whereas those of professional basic courses and professional courses such as biochemistry, cell biology, and molecular biology were extended from 24 class hours to 32 class hours. In this way, two or more comprehensive experiments were added in these courses. This reform ensured that the undergraduate students were able to fulfill the whole procedures of these experiments under the instructions of teachers during class. Meanwhile, the schedules of experiments were arranged in a more flexible way. The teachers responsible for experiments teaching could apply for the experiment periods through an open on-line system, and the comprehensive experiments could be arranged consecutively so as to ensure that these time-consuming experiments could be done continuously to obtain a better teaching result. For example, the course genetic engineering includes nine experiments and should be done continuously. This opening laboratory policy ensured a better teaching result, and almost $90 \%$ of the undergraduate students could fulfill the whole procedure smoothly. 


\section{Introduce technology of virtual reality to biotechnology experiment teaching}

The virtual reality (VR) technology can simulate the circumstances in computer which are difficult to realize in reality or to repeat in the practical teaching [4]. Since 2016, our university has invested RMB 1.7 million to build a provincial VR teaching and demonstration center for agronomy and biotechnology including a VR show room and a multi-media classroom, and nine sets of VR teaching software have been developed and put into use in the experiments teaching such as the virtual simulation software for precision instruments, the virtual simulation software for greenhouse assembling and disassembling, and the virtual simulation software for genetics engineering, etc. This VR center is basically based on an open on-line system, and the students can be trained both in class and after class. After learning in a VR circumstance first, the students were more familiar with the realistic procedures of the experiments, and they would do better when doing the realistic experiments.

\section{E. Stimulate research learning and innovative experiments by undergraduate students}

The research learning and innovative experiment projects are the main parts for promoting the teaching quality of biotechnology undergraduate students [5]. In recent years, our university has laid more emphasis on these projects in order to improve the experiments teaching results. The students retrieved references, wrote scientific projects under the teachers supervision, and then the excellent projects were selected and supported by the university and the Provincial Education Department. Then the students carried on scientific researches with a great interest and finally promoted their experimental skills. In this way, the mode of experiment teaching was stretched and expended effectively. In 2016 and 2017, the biotechnology students applied successfully 27 items of these projects. Among them, four items were supported by the Provincial Education Department. The students published nine articles, and were rewarded three second prizes and four third prizes in the biotechnology competition held by National Education Steering Committee of Biology Specialties of Colleges and Universities. And three teachers in biotechnology specialty were awarded as excellent guide teachers. Most of the students in the biotechnology specialty in our university took part in these projects, and their experimental skills were promoted evidently.

\section{CONCLUSION}

The personnel training goal of the biotechnology specialty in local universities is aiming at the cultivation of specialized talents for the local economic development. Thus, the core contents of the experiments training system of the specialty mainly include the manipulative ability, the innovative ability, and the experiment skill. In recent years, Hunan University of Humanities, Science and Technology has made a series of explorations and reforms on the biotechnology experiment teaching system including the experiment condition improvement, the experimental staffing enhancement, and the experimental curricula innovation etc. The improved experiment teaching system was focused on the promotion of the abilities of the undergraduate students. As a result, the undergraduate students showed a great interest in learning biotechnology, resulting in a satisfying experiment teaching effect. These reforms were welcome by the undergraduate students in the biotechnology specialty and affirmed by all walks of life in the society.

\section{ACKNOWLEDGEMENT}

This research was financially supported by Innovation Base for Postgraduates Cultivation of Hunan Province (2261602) and Research Project of Teaching Reform of Degree and Graduate Education in Hunan (JG2016B106).

\section{REFERENCES}

[1] D. Duan, Y. Liang, S. Chen, X. Ge, and L. Ruan, "Reform and implementation of bioengineering experimental teaching system," Research and Exploration in Laboratory, vol. 30, pp. 111-114, 2011.

[2] Z. Tan, D. Xu, P. Cui, F. Peng, and L. Meng, "Reform and practice of experimental teaching system of bioengineering specialty," Guangdong Chemical Industry, vol. 44, pp. 277-278, 2017.

[3] T. Tang, "Reform and research on experimental course of biochemistry of bioengineering specialty," Experiment Science and Technology, vol. 10 , pp. $35,109,2012$.

[4] F. Gu, "The construction of biology classroom experiment demonstration model based on VR technology," Journal of Ningbo Institute of Education, vol. 13, pp. 138-140, 2011.

[5] Y. Liu, J. Zhang, and H. Yu, "Practice and exploration on implementing college students' innovative experiment plan and constructing innovative personnel training system based on ability cultivation," Experimental Teaching and Management, vol. 29, pp. 21-23, 2012. 